American Journal of Animal and Veterinary Sciences 5 (2): 97-101, 2010

ISSN 1557-4555

(C) 2010 Science Publications

\title{
Influence of Dietary Beta-1,3/1,6-Glucans on Clinical Signs of Canine Osteoarthritis in a Double-Blind, Placebo-Controlled Trial
}

\author{
${ }^{1}$ A.C. Beynen and ${ }^{2}$ E. Legerstee \\ ${ }^{1}$ Vobra Special Petfoods BV, Veghel, The Netherlands \\ ${ }^{2}$ University of Applied Sciences, Van Hall Larenstein, Leeuwarden, The Netherlands
}

\begin{abstract}
Problem statement: There are indications for a beneficial effect of beta-1,3/1,6-glucans on the clinical signs of dogs with osteoarthritis. Data from a controlled trial were necessary to prove or disprove the indications. Approach: A double-blind, placebo-controlled trial with privately owned dogs was carried out to assess the efficacy of a preparation of beta-1,3/1,6-glucans in the treatment of osteoarthritis. With the use of a questionnaire, the clinical signs were evaluated by the owners. For a period of 8 weeks, the test dogs daily received a complete dry food without or with $800 \mathrm{ppm}$ beta1,3/1,6-glucans. There were 23 dogs per experimental group. Results: When compared with the baseline values, the administration of beta-1,3/1,6-glucans significantly improved activity (vitality) and significantly reduced stiffness, lameness and pain. In the placebo group there only was a significant change in the clinical signs of stiffness. When the changes over time for the two groups were compared, there were no statistically significant differences, but the test group showed greater numerical improvement as to the scores for activity, stiffness, lameness and pain. Conclusion: Beta1,3/1,6-glucans can be considered safe and it is suggested that a dose of $800 \mathrm{ppm}$ in a dry food would be beneficial for dogs with osteoarthritis.
\end{abstract}

Key words: Dog osteoarthritis, beta-1,3/1,6-glucans

\section{INTRODUCTION}

Canine osteoarthritis is a joint disease commonly seen in veterinary practice. In severe conditions, the symptoms are chronic pain, lameness and disability. Osteoarthritis is a degenerative and inflammatory condition in which there is a loss of cartilage matrix associated with a release of pro-inflammatory cytokines (Mortellaro, 2003). Osteoarthritis cannot be cured and management aims at the relief of pain through reduction of inflammatory reactions and further breakdown of cartilage. Current treatment involves the use of NonSteroidal Anti-Inflammatory Drugs (NSIADS) to decrease inflammation and consequently pain, but side effects such as vomiting and diarrhea may occur. There are various nutraceuticals on the market that are promoted as safe, effective compounds to manage canine osteoarthritis. They are administered as supplements or incorporated into industrially produced dog foods. However, the efficacy of the generally applied nutraceuticals can be questioned. Reviews of the efficacy show that inappropriate experimental designs were used and equivocal results were obtained (Aragan et al., 2007; Beynen, 2008; Budsberg and Bartges, 2006; Henrotin et al., 2005).
The MacroGard ${ }^{\circledR}$ preparation of beta-1,3/1,6glucans is a highly purified product derived from baker's yeast (Saccharomyces cerevisiae). In the period of August 2002-September 2003, GE Berge at the Nordberg veterinary clinic, Oslo, carried out an open study without a placebo and found a positive effect of beta-1,3/1,6-glucans in dogs with osteoarthritis (unpublished data). Because of the open nature of the study and the absence of a placebo group, the observed decrease in clinical signs of joint disorders cannot be taken as evidence for a beneficial effect of beta-1,3/1,6glucans. It is very likely that placebo effects occur when evaluating the clinical signs of dogs with osteoarthritis (Dobenecker et al., 2002; Gingerich and Strobel 2003; Innes et al., 2003; Pollard et al., 2006).

This study readdresses the efficacy of a preparation of beta-1,3/1,6-glucans in the treatment of canine osteoarthritis. In a double-blind, placebo-controlled trial, privately owned dogs were used and the clinical signs were evaluated by the owners. For a period of 8 weeks, the test dogs daily received a complete dry food without or with 800 ppm beta-1,3/1,6-glucans. Part of the results has been published elsewhere in abstract form (Beynen, 2009). 


\section{MATERIALS AND METHODS}

Animals: Dogs with signs of osteoarthritis were recruited through breed associations, websites with animal news, grooming saloons, veterinarians, animal physiotherapists and hyves. The (potential) participants were informed about the purpose and design of the trial and had to sign a statement on informed consent. Fifty three dogs were subjected to either the placebo or test group. Three dogs did not finish the trial and the trial questionnaires for another four dogs were not complete so that the data for 46 dogs ( 23 per treatment group) were available for analysis. Table 1 shows the characteristics of the dogs as based on the intake questionnaire completed by their owners. There was a wide variety of dog breeds, the major ones being Labrador Retrievers $(\mathrm{n}=5)$, Rottweilers $(\mathrm{n}=5)$, border collies $(n=10)$, crossbreeds $(n=5)$ and others $(n=21)$. The analgetics used were as follows: Metacam $(n=4)$, meloxidyl $(\mathrm{n}=3)$, rimadyl $(\mathrm{n}=5)$ and others $(\mathrm{n}=5)$. In 12 dogs various supplements were used. The owners were instructed to continue as usual without or with the administration of analgetic and supplement during the course of the trial.

Experimental design: Recruitment of the dogs, maintaining contact with the dog owners, supplying of food, data collection and general coordination of the trial was done by EL who was blinded to treatment modality. The eligible dogs were allocated to either the placebo or treatment group by $\mathrm{ACB}$, who kept the treatment code closed until statistical analysis of the data. Allocation was done so that the distribution of the severity of lameness, as based on the intake questionnaire, would be similar among the two groups. All dogs were fed on the same complete dry food (Carocroc Chicken and Rice 23/12, Vobra Special Petfoods BV, Veghel, The Netherlands), which was supplied in $20 \mathrm{~kg}$, blank packaging. The test food contained $800 \mathrm{ppm}$ of a beta-1,3/1,6-glucans preparation (MarcoGard $\AA$, Orffa) which was added prior to extrusion. The foods were sent by courier to the dog owners. The trial lasted 10 weeks. The first two weeks served as a baseline. During the third week the dogs were gradually transferred from their habitual diet to the food supplied. During the fourth week only the food supplied was fed, which was continued for another 8 weeks.

Trial questionnaire: The trial questionnaire was in the form of a web form, which also provided instructions, including a completed example of a question in the format used. The entrance of the web form was protected by a pass word, which could be received by email from EL. The severity of the signs of osteoarthritis was scored by the owners by placing a slider along a horizontal slit. The slit was without any unit, but functioned as a scale in combination with the description. Next to the slit a display was shown, on which the values entered could be seen. The values were expressed on a $0-100$ scale. The slider being located on the left extreme side of the slit corresponded to a value of 0 . A value of 100 was obtained by placing the slider on the right extreme side of the slit. The signs to be scored by owners were: Activity (vitality), stiffness, swelling of joint, lameness, paralysis, pain. Body condition was also scored. The signs were scored on day 0 (start) and weekly afterwards.

To aid in scoring the signs, the following descriptions were given.

Activity (vitality): How active and vital is your dog? Is your dog capable of playing? Does your dog reach the door earlier than you? Is your dog excited when you are taking her/him somewhere?" The scale ran, from "Not active" (extreme left) to "Very active" (extreme right).

Stiffness: How stiff is your dog? Does your dog easily get out of its basket in the morning or does it take time to get started when going for a walk"? The scale ran, from "Very stiff" (extreme left) to "Smooth" (exteme right).

Swelling of joint: "Does your dog have swelling on the site of osteoarthritis? Around the joint with diagnosed osteoarthritis, there may be swelling of either a tough or soft nature". The scale ran from "Marked swelling" (extreme left) to "No swelling" (extreme right).

Table 1: General characteristics of the dogs

\begin{tabular}{lll}
\hline Characteristic & Placebo group $(\mathrm{n}=23)$ & Beta-1,3/1,6-glucans $(\mathrm{n}=23)$ \\
\hline Osteoarhritis diagnosed by veterinarian, yes/no & $22 / 1$ & $17 / 6$ \\
Mean age, years (range) & $8.48(2-16)$ & $8.61(2-15)$ \\
Mean body weight, kg (range) & $27.74(8-62)$ & $30.44(9-85)$ \\
Gender, female/male & $9 / 14$ & $9 / 14$ \\
Use of analgetics, yes/no & $7 / 16$ & $10 / 13$ \\
Use of supplements, yes /no & $7 / 16$ & $5 / 18$ \\
\hline
\end{tabular}


American J. Animal \& Vet. Sci., 5 (2): 97-101, 2010

Table 2: Baseline values and changes over time in the osteoarthritic signs (improvement is indicated by a +sign) and body condition

\begin{tabular}{|c|c|c|c|c|c|c|c|}
\hline \multirow[b]{2}{*}{ Variable } & \multicolumn{3}{|c|}{ Placebo group $(\mathrm{n}=23)$} & \multicolumn{3}{|c|}{ Beta-1,3 /1,6-glucans $(\mathrm{n}=23)$} & \multirow[b]{2}{*}{$\begin{array}{l}\text { p-value for between- } \\
\text { group difference } \\
\text { in change ( } 2 \text {-tailed) }\end{array}$} \\
\hline & Baseline & $\begin{array}{l}\text { Change versus } \\
\text { baseline (range) }\end{array}$ & $\begin{array}{l}\text { p-value } \\
\text { for change } \\
\text { (2-tailed) }\end{array}$ & Baseline & $\begin{array}{l}\text { Change versus } \\
\text { baseline (range) }\end{array}$ & $\begin{array}{l}\text { p-value } \\
\text { for change } \\
\text { (2-tailed) }\end{array}$ & \\
\hline Activity & 53.3 & $+4.00(-1.17$ to +9.17$)$ & 0.123 & 54.8 & $+8.65(+3.30$ to +14.00$)$ & 0.003 & 0.201 \\
\hline Stiffness & 39.5 & $+9.23(+1.45$ to +17.01$)$ & 0.022 & 40.4 & $+15.28(+8.76$ to +21.79$)$ & 0.000 & 0.223 \\
\hline Swelling & 82.0 & $+2.99(-1.65$ to +7.63$)$ & 0.196 & 79.3 & $+4.92(-1.45$ to +11.30$)$ & 0.123 & 0.612 \\
\hline Lameness & 64.3 & $+6.38(-2.59$ to +15.34$)$ & 0.154 & 67.3 & $+10.00(+2.22$ to +17.79$)$ & 0.014 & 0.530 \\
\hline Paralysis & 94.8 & $+0.15(-0.94$ to +1.23$)$ & 0.783 & 95.6 & $+1.16(-1.99$ to +4.31$)$ & 0.453 & 0.531 \\
\hline Pain & 71.1 & $+4.75(-1.11$ to +10.62$)$ & 0.107 & 72.8 & $+9.32(+3.07$ to +15.56$)$ & 0.005 & 0.275 \\
\hline Body condition & 49.6 & $-2.81(-6.47$ to +0.84$)$ & 0.125 & 50.8 & $-0.33(-2.67$ to +2.00$)$ & 0.770 & 0.242 \\
\hline
\end{tabular}

Lameness: Is your dog lame or does it not use one leg at all? Watch your dog carefully to ascertain whether or not there is a change of the degree of lameness during the trial". The scale ran from "Very lame" (extreme left) to "Not lame" (extreme right).

Paralysis: Does your dog show signs of paralysis? Sometimes, osteoarthritis can lead to paralysis. The dog usually wobbles its hind body and has difficulty rising". The scale ran from "Hind body fully paralyzed" (extreme left) to "No paralysis" (extreme right).

Pain: Does the osteoarthritis cause pain in your dog? Does your dog growl or scream when she/he gets up or makes a wrong movement. Does your dog indicate pain or does she/her try to bite you when touching certain joints". The scale ran from "Usually an expression of pain" (extreme left) to "Never an expression of pain" (extreme right).

Body condition: What is the body condition of your dog? In an obese dog, the ribs are not visible and are covered by a layer of fat tissue. In addition, the belly is not slimmer than the chest and thus shows no waist. A dog with normal body condition has ribs that are just visible and shows a waist. A skinny dog has pronounced ribs". The scale ran from "Very skinny" (extreme left) to "Very fat" (extreme right).

Data analysis: After scoring by the owner of the clinical signs on the web form, the values were automatically sent to EL by mail. To calculate the baselines, the values for day 0 , week 1 and 2 were averaged per variable per dog. To calculate the final values, those for weeks 9-11 were averaged. For each dog and each variable, the change over time was calculated. To identify treatment effects, the changes over time for the placebo and test group were subjected to the Student's $t$ test with $p<0.05$ as criterion of statistical significance.

\section{RESULTS}

Table 1 shows that the general characteristics of the placebo and test group were similar, except that in the test group less dogs had been diagnosed for osteoarthritis by a veterinarian. The baseline values for the clinical signs of osteoarthritis were comparable for the test and placebo group (Table 2). When compared to the baseline values, the ingestion of beta-1,3/1,6-glucans significantly improved the signs of activity (vitality), stiffness, lameness and reduced pain (Table 2). In the placebo group there only was a significant change in the signs of stiffness. When the changes over time of the two groups were compared, there were no statistically significant differences.

\section{DISCUSSION}

Taking the stand that beta-1,3/1,6-glucans are effective in the treatment of canine osteoarthritis should be based on a likely mechanism of action and the observation that in double-blind clinical trials it provokes a significantly better effect than a placebo. The latter prerequisite is not unequivocally met by the present trial. In the course of the trial, the treatment versus placebo group showed a greater numerical improvement as to the scores of activity, stiffness, lameness and pain, but the differences between the treatments did not reach statistical significance. In the light of the systematic, positive effects of the beta1,3/1,6-glucans, it could be suggested that the lack of statistical significance is caused by insufficient statistical power rather than by an inefficacy of the supplement.

The interpretation of the present data in that beta1,3/1,6-glucans may improve the clinical signs of osteoarthritis is further supported by looking at the changes over time in each group. When compared with the baseline values, the improvement of activity and lameness and the decrease in pain were statistically significant in the treatment group, but not in the placebo 
group. As mentioned above, in an open, non-controlled trial, G.E. Berge found a beneficial effect of beta1,3/1,6-glucans on canine osteoarthritis. That study by itself cannot be taken as evidence for a beneficial effect of beta-1,3/1,6-glucans. However, the current data and those of G.E. Berge taken together do point at efficacy of beta-1,3/1,6-glucans in the treatment of canine osteoarthritis. Clearly, further clinical trials are required for definite proof.

For the use of beta-1,3/1,6-glucans in the treatment of canine osteoarthritis to have a scientific basis, it should be possible to explain in molecular terms how it inhibits inflammation and/or inhibits breakdown of the cartilage matrix. Research in pigs (Li et al., 2006) has demonstrated that the feeding of beta-1,3/1,6-glucans reduced the plasma concentrations of the proinflammatory cytokines, IL-6 and TNF $\alpha$ and raised the concentration of the anti-inflammatory cytokine, IL-10. Thus, the intake of beta-1,3/1,6-glucans may reduce inflammation in canine osteoarthritis and thereby reduce pain. TNF $\alpha$ also stimulates the production of matrix metalloproteinase-3 (MMP-3) by chondrocytes (O'Connor and Fitzgerald, 1994). MMP-3 is involved in the degradation of collagen molecules in the cartilage matrix. It could thus be suggested that the positive effect of beta-1,3/1,6-glucans is caused by inhibition of the degradation of ollagen in the cartilage matrix associated with a reduction in inflammation and pain sensation.

The clinical signs of the dogs were evaluated by their owners which had been instructed equally and carefully. It has been reported that the owners' evaluation of osteoarthritic signs in dogs correspond well with those of veterinarians (Innes et al., 2003). Further aspects also indicate that the present observations are not biased. The double-blind nature of the trial excluded any observer bias. The general characteristics of the two groups were similar so that allocation bias is unlikely. Changes in body weight are associated with changes in the severity of canine osteoarthritis (Impellizeri et al., 2000; Mlacnik et al., 2006). During the course of this study, body condition of the dogs remained constant in both treatment groups so that the positive effect of beta-1,3/1,6-glucans on osteoarthritis can be considered independent of body weight.

\section{CONCLUSION}

This study does not provide solid evidence that dietary beta-1,3/1,6-glucans diminishes the clinical signs in dogs with osteoarthritis, but a beneficial effect of clinical relevance is acceptable. Beta-1,3/1,6-glucans are safe (Lehne et al., 2006). Beta 1,3/1,6-glucans are heat stable and can be added to dog food prior to extrusion. This study indicates that a dose of about $800 \mathrm{ppm}$ in a dry food would be beneficial for dogs with osteoarthritis.

\section{REFERENCES}

Aragan, C.L., E.H. Hofmeister and S.C. Budsberg, 2007. Systematic review of clinical trials of treatments for osteoarthritis in dogs. J. Am. Vet. Med. Assoc., 230: 514-521. PMID: 17302547

Beynen, A.C., 2008. Optimalisering van een dieetvoeder voor honden met ostearthrose. Dier-enArts, 23: 16-21.

Beynen, A.C., 2009. Een dieetvoeder voor honden met osteoarthrose. Dier-en-Arts, 24: 446-451.

Budsberg, S.C. and J.W. Bartges, 2006. Nutrition and osteoarthritis in dogs: Does it help. Vet. Clin. North Am. Small Anim. Pract., 36: 1307-1323. PMID: 17085237

Dobenecker, B., Y. Beetz and E. Kienzle, 2002. A placebo-controlled double-blind study on the effect of nutraceuticals (chondroitin sulfate and mussel extract) in dogs with joint disease as perceived by their owners. J. Nutr., 132: 1690-1691. PMID: 12042495

Gingerich, D.A. and J.D. Strobel, 2003. Use of clientspecific outcome measures to assess treatment effects in geriatric, arthritic dogs: Controlled clinical evaluation of a nutraceutical. Vet. Therap., 4: 56-66. PMID: 12756636

Henrotin, Y., C. Sanchez and M. Balligand, 2005. Pharmaceutical and nutraceutical management of canine osteoarthritis: Present and future perspectives. Vet. J., 170: 113-123. PMID: 15993795

Impellizeri, J.A., M.A. Tetrick and P. Muir, 2000. Effect of weight reduction on clinical signs of lameness in dogs with osteoarthritis. J. Am. Vet. Med. Assoc., 216: 1089-1091. PMID: 10754668

Innes, J.F., C.J. Fuller, E.R. Grover, A.L. Kelly and J.F. Burn, 2003. Randomized, double-blind, placebocontrolled parallel group study of P54FP for the treatment of dogs with osteoarthritis. Vet. Rec., 152: 457-460. PMID: 12723628

Lehne, G., B. Haneberg, P. Gaustad, P.W. Johansen and H. Preus et al., 2006. Oral administration of a new soluble branched beta-1,3-D-glucan is well tolerated and can lead to increased salivary concentrations of immunoglobulin A in healthy volunteers. Clin. Experim. Immunol., 143: 65-69. PMID: 16367935 
Li, J., D.F. Li, J.J. Xing, Z.B. Cheng and C.H. Lai, 2006. Efects of $\beta$-glucan extracted from Saccharomyces cerevisiae on growth performance and immunological and somatotropic responses of pigs challenged with Escherichia coli lipopolysaccharide. J. Anim. Sci., 84: 2374-2381. PMID: 16908640

Mlacnik, E., B.A. Bockstahler, M. Muller, M.A. Tetrick and R.C. Nap et al., 2006. Effects of caloric restriction and a moderate or intense physiotherapy program for treatment of lameness in overweight dogs with osteoarthritis. J. Am. Vet. Med. Assoc., 229: 1756-1760. PMID: 17144822
Mortellaro, C.M., 2003. Pathophysiology of osteoarthritis. Vet. Res. Commun., 27: 75-78. PMID: 14535372

O'Connor, C.M. and M.X. Fitzgerald, 1994. Matrix metalloproteinases in lung disease. Thorax, 49: 602-609. PMID: 8016800

Pollard, B., W.G. Guilford, K.L. Ankenbauer-Perkins and D. Hedderley, 2006. Clinical efficacy and tolerance of an extract of green-lipped mussel (Perna canaliculus) in dogs presumptively diagnosed with degenerative joint disease. N. Zealand Vet. J., 54: 114-118. PMID: 16751841 